\title{
K-12, university students and Robots: an early start
}

\author{
Filomena Soares, Fernando Ribeiro, Gil Lopes, \\ Celina P. Leão \\ School of Engineering, University of Minho \\ Guimarães, Portugal \\ \{fsoares, fernando, glopes\}@dei.uminho.pt, \\ cpl@dps.uminho.pt
}

\author{
Samuel Santos \\ Basic School of Castêlo da Maia \\ Maia, Portugal \\ samusic@hotmail.com
}

\begin{abstract}
This paper describes a study carried out with $\mathbf{K - 1 2}$ students. This study proposes tounderstand the motivation of these students in the use of robots in the Project Area curricular unit and whether they want to continue their studies in technology areas. K-12 students participated in the RoboParty ${ }^{\circledR}$ event, where the main task is to assemble and program a robot. In other words, the students, in a simple and entertaining way and supported by qualified tutors, learned how to build a robot. At the end of the academic year, a questionnaire was applied to identify and evaluate the K-12 students' opinions regarding the experience. The students' reaction to this experience was quite positiveas well the direct contact with the university environment.
\end{abstract}

Keywords-K-12;partnership;questionnaires; robotics.

\section{INTRODUCTION}

An innovative teaching/learning experience was tested in Castêlo da Maia Basic School (CMBS), Portugal, with students from the $6^{\text {th }}$ grade, running through a partnership with School of Engineering of University of Minho (SEUM).

The topic "Robotics" is discussed and developed by a group of students aged between 11 and 12 years, within the official school system. This simple fact is itself a curious and unusual element that makes the project unique. When considering theproject results and the social impact arising from both school responsible and the community, we are more committed to the idea of novelty. The approach of robotics in education, in this case, yet so far away from specific areas learned at university, opens a new precedent and raises several questions, which identified, should not pass without an analysis. The main idea is not to be ambitious to the point of validating the issue of robotics in the process of teaching and learning at the second cycle of basic education. However, the relevance of teaching robotics and their importance, in pedagogical terms, regarding the results, must be considered.

To justify and demonstrate the relevance and significance of pedagogic approach of robotics in education is therefore our basic question.In order to describe the work developed by a group of elementary school and university teachers, this article is divided in seven sections. After an overview of the main issue of this project, in Section 1, a brief review on teaching/learning experiences among K-12 students in the robotics topic is presented. In the followings sections (3 to 5) the project, the class and the RoboParty ${ }^{\circledR}$ event at University are presented and described. The questionnaire and the corresponding statistical analysis is discussed in section 6, ending with the conclusions of this work.

\section{TEACHING/LEARNING EXPERIENCES}

Some K-12 collaborative works have been running in different graduation courses [1-2]. Nevertheless,it is authors' believethat similar projects in the topic "Robotics", at least in the age group concerned, are not being developed in Portuguese schools.

The approach of Robotics as a subject of study in the Portuguese basic education is in this circumstance, a novelty. Thus, the lack of work already undertaken in this context prevents us to perform a comparative study. The question is to find references and scientific support to the link between eleven and twelve year's old children and their relationship to the object "Robot".

Following this trend, the idea is to present studies showing the importance of the robot in the imaginary plane, in order to understand the role and to what extent will go the influence of robotics on the young students. What is the impact of the contact to the robot as a virtual pet or toy or amusing book hero or electronic game action at the level of the primary motivations and thus understand what was behind the decisions taken by the students during the project development.

While any abstract object decreases the emotional effect on the individual, the robot is perceived as an abstract object as if it were a living being. This relationship is very inquisitive and has already therapeutic applications such as project Kaspar, a robot that helps autistic children [3], and other studies that use Lego robots to promote the communication with adolescents with autism and mental impairments [4]. The relationship Robot/Child contributes to improvements in social behavior and communication. The study on the relationship between robots and pre-teens as a way of learning course content is developed by Antonio Barros and Flávia Jr [5]. In their study, they show optimistic results regarding the use of robotics as a further element of didactic teaching. The theme of the robot as a catalyst in the process of teaching and learning is further deepened by Daniel Schwartz and Sandra Okita [6] that expose how children understand the concept and role of memos robot learning. 


\section{THE PROJECT}

Before developing the approach made to the subject Robotics, it must be clarified how this approach arises in the specific context of basic education, given that the curriculum of the various disciplines does not address or even remotely close to the theme "Robotics". The introduction to the subject was included in the curriculum of Project Area discipline. According to Law No. 6 / 2001 of 18th January, Project Area discipline is aimed to improving the quality of teaching in particular, to design, implement and develop interdisciplinary projects. In this context, the lack of book manuals or specific curriculum provides teachers and students an extraordinary freedom of action. Throughout this one year project, students develop their project on Robotics with the assistance and support of teachers,from school and university, and parents.

The class was divided in nine groups.The project started with a two-hour seminar organized and moderated by students and performed by a teacher from the university with an exhibition of different types of robots. Then, each group defined a particular topic: Robotics at Home andat Space, Robotics in Medicine and in Industry, Sensors, Nano-robotics, Programming Robots, Telecommunications and Robotic Toys.

Group work was carried out not only in the classroom and in the library with the support of many teachers but also at home with support from parents.Teachers in charge of the Project Area discipline planned and provided the conditions to meet the resource needs required to achieve project goals.

\section{A. Skills}

Project Area teachers selected the following skills to be developed within the teaching/learning process:

- Developing Social Skills (communication, teamwork, conflict management, decision making, evaluation ...);

- Learning by doing;

- Connecting theory to practice;

- $\quad$ Promoting the multiple capabilities of the student;

- Learning to solve problems, based on existing resources and situations;

- Developing research and intervention skills, promoting the articulation of different disciplinary knowledge;

- Developing written expression, oral, technological and artistic skills;

- Developing skills for selecting and processing information;

- Developing curiosity, initiative, persistence, responsibility and creativity;

- Creating working methodologies by establishing milestones and priorities.

- Developing strategies for individual and group work;

- $\quad$ Listening to others and make value judgments.

- Increasingself-esteem and self-confidence;

- Developing the skills of self-and peer assessment.
The correct choice of skills provided a solid and broad base of work, which was fundamental to the directives of the work performed.

\section{B. Materials and Resources}

For this project the school board provided a space for storing materials. The fact that the project had a dedicated space where students could develop and store all kind of materials needed to perform the activity was very important, if not decisive, to the project development. The materials used were from various sources, among others: school request, offer or gift, temporary loan.

Some of the employed materials (new or recycled) as well as informatics means were:

Materials: steward ship materials, appliances, electrical and electronic obsolete equipment,electric cables, printed boards unusable, tin, soldering irons, obsolete computers, newspapers, magazines.

Resources: network computer school and unlimited access to the internet, library and all the resources available to media library, multimedia projector and interactive whiteboard.

The close collaboration between school and family was central to the implementation of this project.

\section{Interdisciplinary}

The Project Area is an interdisciplinary subject. It aims to create a space of common thought among all disciplines. Sharing and benefiting from this cross implementation, all subjects taught in 6th grade, actively cooperated trying to find specific content in their curricula that would adapt in any way to the robot. By integrating robotics for various contents was intended to fundamentally expand the discussion of the topic and theme Robotics to diverse areas of knowledge; every teacher could support the class curriculum and keep students motivated and interested. Interdisciplinary was from our point of view achieved, and was formalized in the various meetings of the class council. The results of this interactive content, was rated excellent at the last meeting of the class council by all representatives. It is not always easy to combine extra disciplinary concepts in curricula as they have an extensive timetable. However, from the beginning there was empathy to the subject. The uniqueness of the approach of Robotics in the Project Area for a 6th year acted as an active target involving all the teachers. When considering involving students in a project or in an innovative idea, it is also important that teachers must be motivated and feel involved. In this particular case, we consider to be a success, given the results obtained.

\section{Activities Planning}

The project carries onduring the school year divided in three terms. The planned activities were divided as follows: 
During the $1^{\text {st }}$ Term (September 09 to December 09):

- Identifying the scope of the problem: Robotics;

- Identification of problems: creation of working groups and sub-themes.

- Planning of work: Defining the competencies of the activities of the materials and schedule of work;

- Fieldwork: Research information about the subtopics;

- Organization of a colloquium on the theme of robotics held on December 3rd in the auditorium of EB 2,3 do Castêlo da Maia by Dr. Gil Lopes, from University of Minho, as guest speaker.

During $2^{\text {nd }}$ Term (January 10 to March 10 ):

- Treatment of data collecting and research;

- Planning/organization and participation in the event at University of Minho (Guimarães pole) RoboParty®;

- Integration of all activities in the Comenius Project approved in the teaching;

- Completion of written assignments;

- Participation of various groups in the activity "Cradle of Ideas”.

During $3^{\text {rd }}$ Term (April 10 to June 10):

- Development of a robot;

- $\quad$ Perform a presentation on robotics;

- Reflection on skills acquired;

- Assessment of work: Self-and peer assessment.

\section{CLASS CHARACTERIZATION}

The target groups consisted of a class of 28 students, 12 boys and 16 girls with a mean age of 11 years. Most of them came together from preschool. This fact might have encouraged the interaction in group work. All students live with their families. Almost all of them have older brothers and sisters, some finalists in high school. Their parents are around the average age between 40-45 years. Most of the parents have a higher graduation course. They support their children in studies at home. 26 out of the 28 students aim to take a university course. It is worth mention that this class is the one with more prizes of Honor and Excellence in the previous school year.

The family support provided by parents is clearly a contribution to the choices and interests of students. The fact of having older brothers and sisters in high educational levels may also have influenced the attitudes of the class.

\section{FORTNIGHT AT UNIVERSITY - ROBOPARTY® EVENT}

At Easter time, K-12 students spent a fortnight (from Friday to Sunday) in SEUM, participating in RoboParty ${ }^{\circledR}$ event (www.roboparty.org/en/).

Junior RoboCups and other robotic events in Europe and in the rest of the World are based on competition whereas the
RoboParty® event is of a pedagogical type. In other words, for robotic competitions youngsters take their already built robot to the competition in order to participate in the event by competing for better rankings. In most cases they were not the builders or programmers of their own robots, just know how to turn it on/off. At RoboParty ${ }^{\circledR}$ they learn how to build and program a specific robot during the whole event. Tests, fine tuning, optimization and algorithm improvement is made when they put their robots to test on group trials with no competition sentiment, just for the sake of getting to know their robot better and to get the most out of it [7-9].

Fig. 1 and Fig. 2 show the robots built by the students that participated in the event. The idea is that, by taking a hands-on approach to learning, K-12 students learned by doing rather than through lectures and memorization. RoboParty ${ }^{\circledR}$ is an educational event that gathers teams of four students, during 3 days/2 nights to teach how to build autonomous mobile robots in a simple and entertaining way, supported by qualified tutors. Initially, a short course was given to teach the first steps in electronics, robot programming and mechanical construction. Afterwards, a robotic kit developed by the company SAR (Soluções de Automação e Robótica, www.sarobotica.pt/) and by Minho University was supplied to be assembled by the participants (mechanics, electronics and programming), belonging to the team at the end of the event.

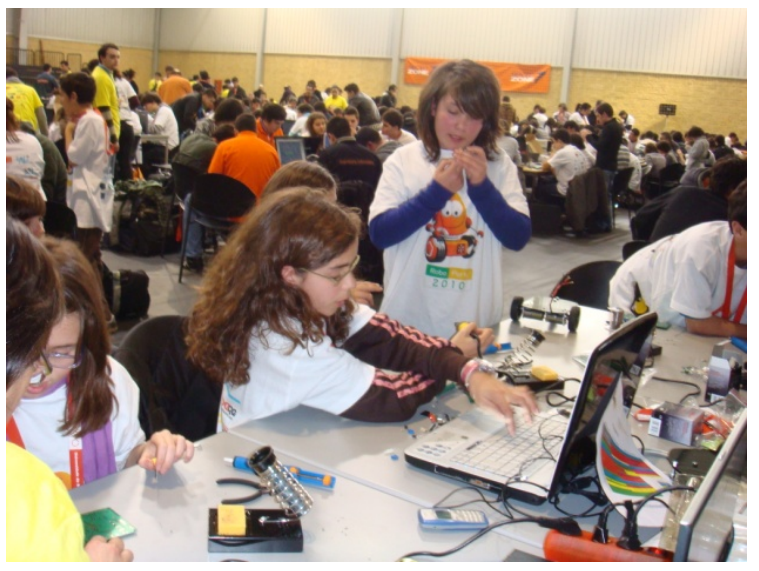

Figure 1. Roboparty event

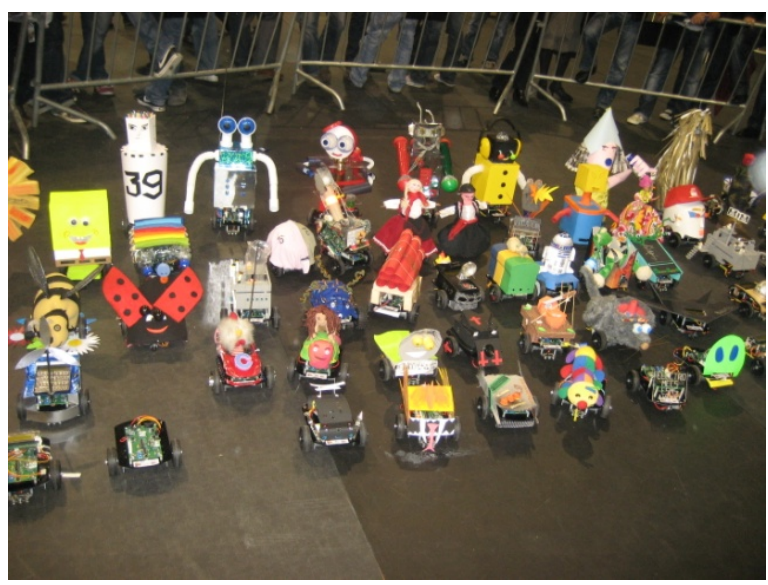

Figure 2. Roboparty event - some robots assembled 
The tutors, University students, followed team's work closely in all stages in order to assure that every robot worked properly at the end.

In parallel, there were entertainment activities such as sports, music, Internet, games, parties. Students stayed overnight in the venue as in a non-stop LAN party with educational and pedagogical aims. Rules of important national and international robotic competitions were previously explained.

To perform all these activities, the help of a group of undergraduate engineering students was very important. They helped not only to take care of the K-12 students during the fortnight period, but also and most important, help in dissemination of concepts, skills and strategies through robotics.

\section{K-12 STUDENTS' AtTITUde EvaluAtion}

To better understand and analyze what motivated K-12 students to build and study robots, to participate in the RoboParty ${ }^{\circledR}$ and how they see the university environment, a questionnaire was developed. The questionnaire was applied directly to the K-12 students at the end of the academic year (June 2010).They were distributed to the students and conducted in a traditional classroom where each student wrote his/her answer directly in the questionnaire paper sheet during a period of around 5 to 10 minutes.

The questionnaire has four main parts: (1) student characterization (age and gender), (2) evaluation of the RoboParty ${ }^{\circledR}$ participation (general opinion, expectations, rating the experience, work done, among others), (3) University (information concerned to the students future area of study), (4) Project Area theme (students' importance, difficulties, areas of interest). It was, essentially, composed by closed questions, still with some open questions of spontaneous response. This choice took into account not only the age of the respondents but also to uniform and facilitate the analysis. The statistical analysis of the questionnaires was done using SPSS software (Version 17.0) [10].

\section{A. K-12 students' characterization}

A group of 26 students responded to the challenge, with an average around 11.38 years old (std. deviation of 0.5 ) with $61.5 \%$ of female students. It is important to state that for $81 \%$ of the K-12 students it was the first time that they participated in this type of experience against $9.5 \%$ who participated in this initiative for the third time (2 K-12 students).

\section{B. RoboParty ${ }^{\circledR}$ and Project activities K-12 students' analysis results}

In general, K-12 students are completely and very satisfied with the RoboParty ${ }^{\circledR}$ (86.4 and $13.6 \%$, respectively). Similar behavior when asked if the RoboParty® exceeded their expectations: $68.2 \%$ completely and $31.8 \%$ very much.
In average, the K-12 female and male students show similar behavior when asked to identify what they liked most in the RoboParty ${ }^{\circledR}(p>0.05)$. This question was done in accordance with a level of satisfaction: from 1 (the worst choice) to 5 (best choice). Being in contact to the university environment was identified by $70 \%$ of the students as the most positive aspect (Fig. 3a) followed by the need to build the robot identified by $66.7 \%$ of the students (Fig. 3b), in opposition to the $15.8 \%$ that identify the most negative facet of the RoboParty ${ }^{\circledR}$ as the need to program the robot (Fig. 3f). Nevertheless, for the six offered choices, the average evaluation was very positive (around 4.3, almost 5, the best choice).
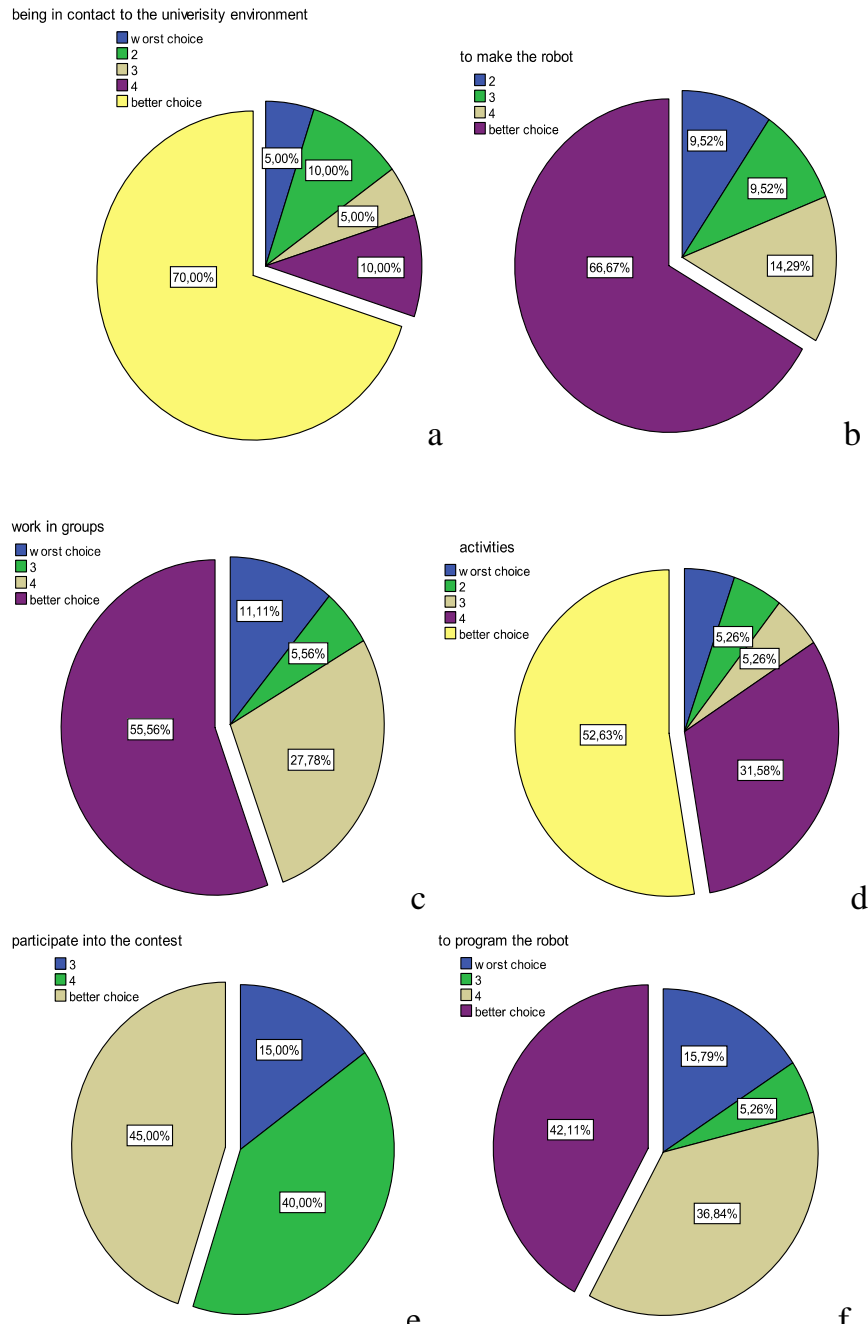

d

Figure 3.Obtained results to the question "identify what do you like most in the robotparty" (a) being in contact to the university environment, (b) to make the robot, (c)work in groups, (d) activities, (e) participate into the contest, (f) to program therobot.

Concerning the project area "Robotics", the students identified the possibility of building a robot as the task that they like the most: $42.3 \%$, as illustrated in Fig. 4, followed by the possibility to carry out an applied project (23.1\%) and to work in groups (15.4\%). 


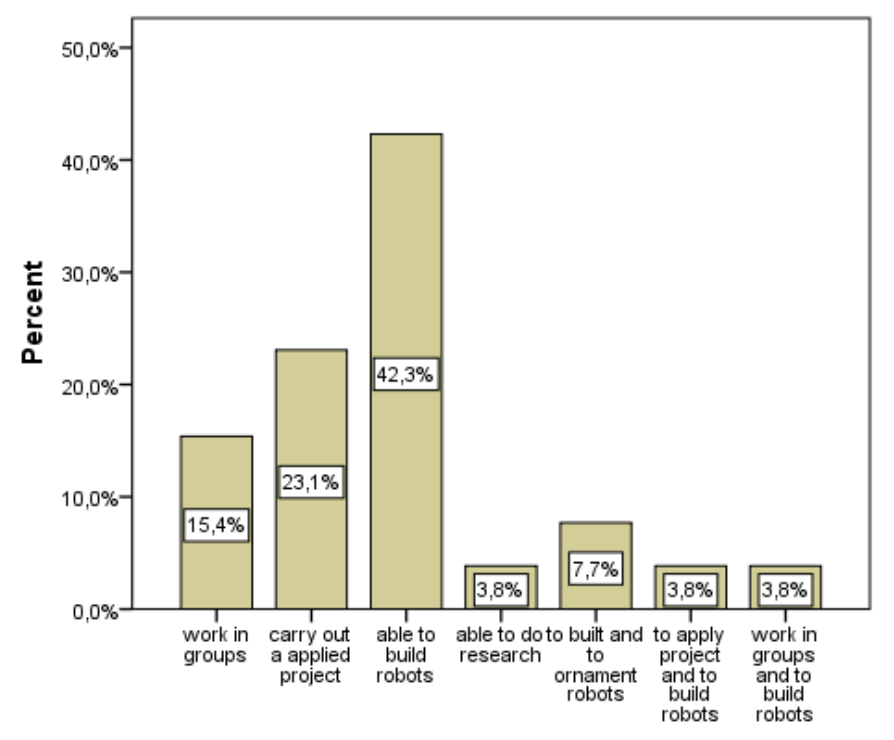

Figure 4.K-12 students' answer to the question "What did you like the most in the project area theme?”

Independently of the gender, the K-12 students shows similar behavior concerning to the degree of difficulty in performing tasks in the project area (Fig. 5): about 53\% of the students identified the difficulty as medium and only about $7 \%$ identified that had not any difficulties in the preparation of the robot.

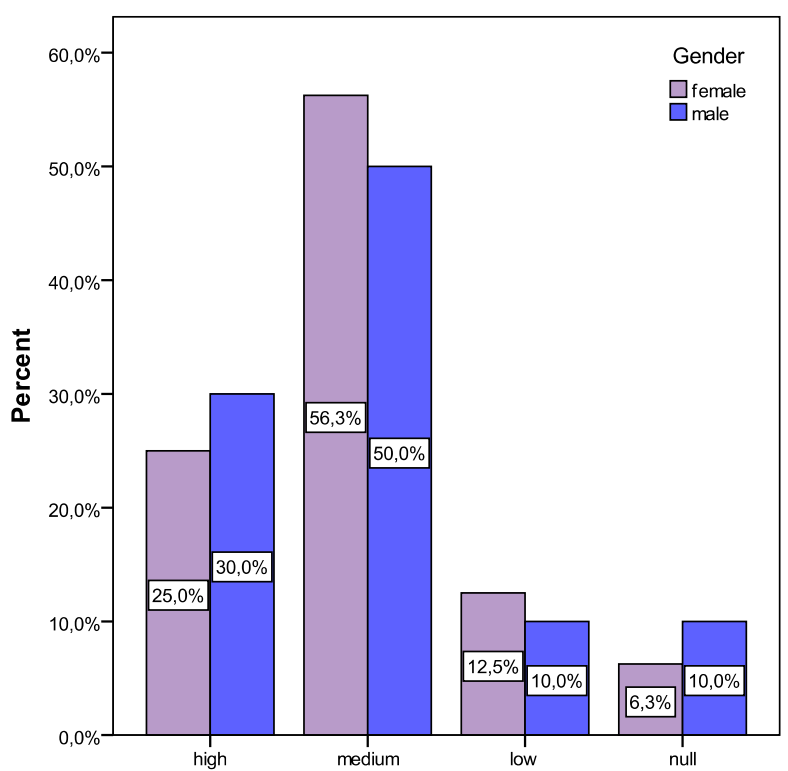

Figure 5. K-12 students' answer to the question "Degree of difficulty in performing tasks in the project area”

It is worthy to mention the $\mathrm{K}-12$ students' perception regarding project area defined skills. When asked "who do you think worked more in the robot?”, $60.0 \%$ of them identified that all of the group members worked equally (Fig. 6). Communication, teamwork, conflict management and decision making were social skills acquired. The role of the Tutors (University students) was also mentioned (by 20.0\% of the students) as good helpers, having students the responsible of robot's assembly.

Notice that, female and male K-12 students show a different behavior when asked about the course that, at the moment, they would like to take (Fig. 7): engineering the first choice for $87.5 \%$ and $43.5 \%$ for male and female students, respectively, opposing to the choice of arts only by the female students $(43.5 \%)$.

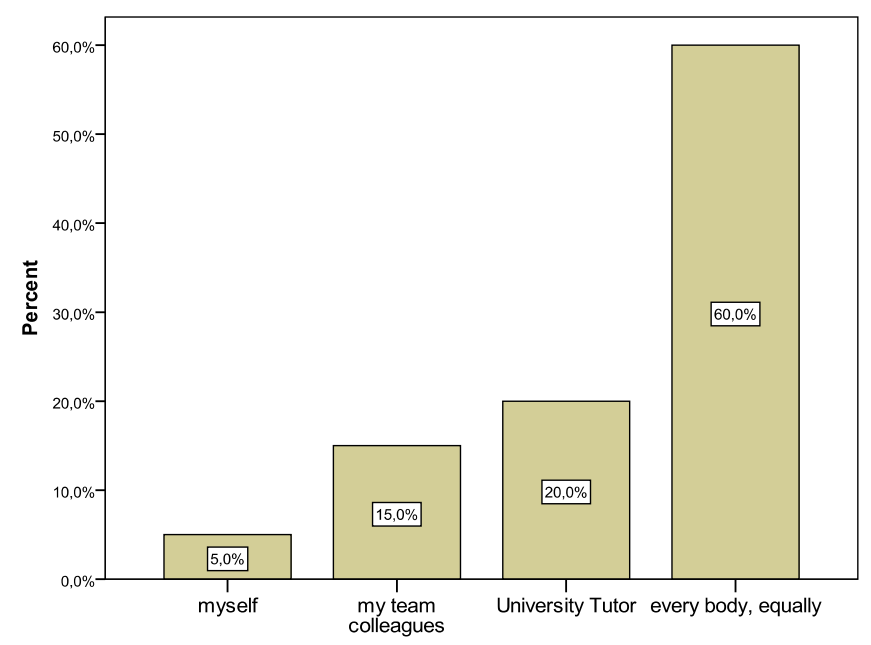

Figure 6. K-12 students' answer to the question "Who do you think worked more in the robot?”

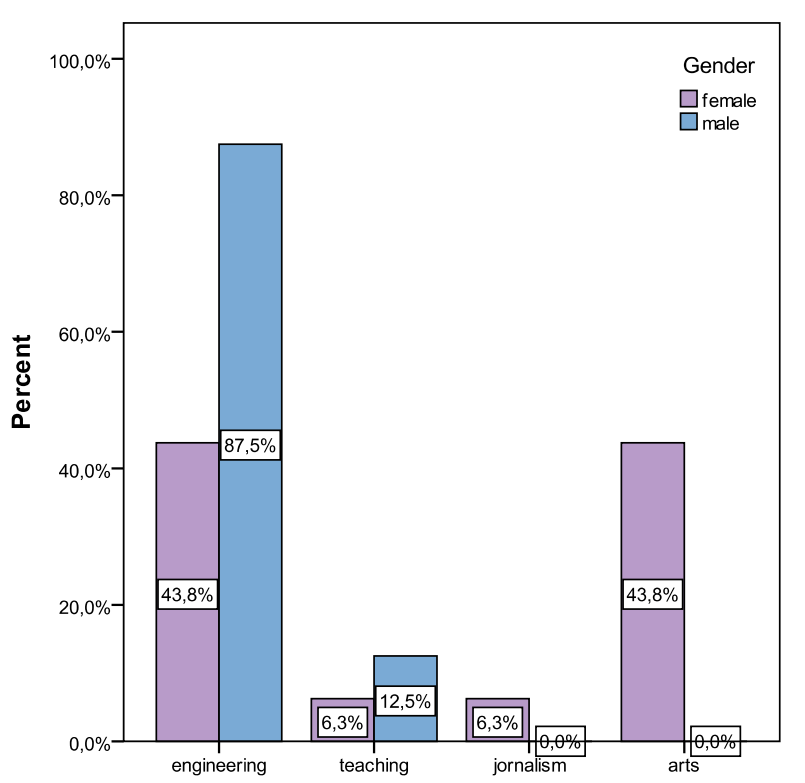

Figure 7. K-12 students' answer to the question "Which course, at this moment, you would like to take?” 
It was interested to observe that the $\mathrm{K}-12$ students that mentioned that they would like to take an engineering course, $61.5 \%$ mentioned that the most positive aspect of the RoboParty ${ }^{\circledR}$ was to build the robot.

\section{CONCLUSIONS}

The choice of Robotics topic wasthe starting point for a unique experience that has provided the school community to approach a subject not commonly found in a second cycle of education.

The Project Area subject had the support from the school board, teachers, parents and also the university community, allowing ideal conditions for the success of the teaching and learning process. Students' behavior and punctuality has evolved over the three terms, concluding the $6^{\text {th }}$ grade with class average of 4.4 on a scale from 1 to 5 . As regards attitudes, there were also significant changes, noting an increased commitment and active participation throughout the school year. During project development emerged a common identity and language among students.

This project demystified the idea that robotics to children, is based only on the field of imagination, catalyzed by icons cartoons or playing video games or virtual pets and the only physical contact with robots will be in the field of play as a toy. This opens a new paradigm. It was proved that a first successful contact with Robots can be achieved at elementary schools. Robotics worked as a catalyst for motivation to study and interest in school as well in students' behavior and approval. It is not possible to deduce that this project had a direct influence on the grades in a specific curricular unit. However, their soft skills and their overallmotivation towards school environment were significantly improved. 12 years students were able to weld components in a printed circuit board, they were able to mount the mechanical parts of the robot, they manage to program simple line code in the robot core, and they participate in contests with older students. The project captivated the entire school community and also drew the attention of many elements of civil community. The students that participated in the project are about to start a new cycle of study. They will bestudying in different schools or classes. So, planning similar activities with this group will not be possible.
The program benefits students and teachers on both ends of the spectrum. Basic school students involved in the program can work with up-to-date themes generally presented to older students. In addition, Basic-school teachers can update their knowledge of the subjects and form a better understanding of project-based learning; University teachers can promote their graduation engineering courses near prospective students.

\section{REFERENCES}

[1] S.E Powers, B. Brydges, P. Turner, G. Gotham, J.J. Carroll, and D.G. Bohl "Successful Institutionalization of a K-12 - University STEM Partnership Program.” In: Proceedings of the 115th Annual ASEE Conference \& Exposition, Pittsburgh PA, June, 2008.

[2] M.U. Bers,and M.Portsmoresl, "Teaching Partnerships: Early Childhood and Engineering Students Teaching Math and Science Through Robotics”, Journal of Science Education and Technology, vol. 14, No. 1,2005, pp.59-72.

[3] B. Robins, K. Dautenhahn, and P. Dickerson, "From Isolation to Communication: A Case StudyEvaluation of Robot Assisted Play for Children with Autism with a Minimally ExpressiveHumanoid Robot”, Second International Conferences on Advances in ComputerHumanInteractions, 2009.

[4] Sandra Costa, Cristina Santos, Filomena Soares, Manuel João Ferreira and Maria de Fátima Moreira, "Promoting the interaction amongst autistic adolescents using robots”, EMBC 2010,32nd Annual International Conference of the IEEE Engineering in Medicine and Biology Society, Buenos Aires, Argentina, 31 August - 4 September, 2010.

[5] António F. L. Jacob, and Flávia A. Barros, “Utilizaçãode robôs de conversação como meio de aprendizagem para crianças e pré adolescentes”, Anais do XXVIII Congresso da SBC, Universidade de Pernambuco, Brasil, 2008 (in Portuguese).

[6] Sandra Y. Okita, and Daniel L Schwartz, "Young Children's understanding of animacy and entertainment robots”, International Journal of Humanoid Robotics (IJHR).vol 3, Issue: 3, 2006 pp. 393-412 (DOI: 10.1142/S0219843606000795).

[7] A. Fernando Ribeiro, "Building a robot to use in school - teachers and students learning together", $5^{\text {a }}$ international conference on Hands on Science, 13-17 October 2008, Olinda, Brasil, ISBN: 978-989-95095-3-5, pp 161-169.

[8] A. Fernando Ribeiro, "New ways to learn science with enjoyment Robotics as a challenge", 6 ${ }^{\mathrm{a}}$ International Conference on Hands On Science, Science for All. Quest for Excellence. 27-31 October 2009, Science City, Ahmedabad, India, ISBN: 978-989-95095-5-9, pp 15-23.

[9] Ribeiro, A. Fernando, Lopes, Gil, "Summer on Campus - Learning Robotics with fun", in Proceedings of HSci2010 - 7th International Conference on Hands-on Science, 21-31 July 2010, Creta, Greece

[10] SPSS an IBM Company (n.d.), SPSS 17.0. Available: http://www.spss.com/ (accessed in December 2010) 